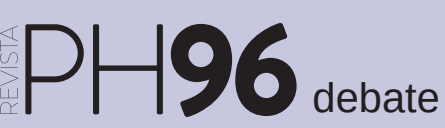

a debate Memoria democrática en la construcción de la historia y el patrimonio

| coordina Josefina Cuesta Bustillo

\title{
Función simbólica del patrimonio
}

Asunción Cobo Gómez | graduada en Humanidades y estudiante del máster Gestión cultural e Industrias creativas de la Universidad de Alcalá

URL de la contribución <www.iaph.es/revistaph/index.php/revistaph/article/view/4291>

Abordar desde una perspectiva imparcial el tema de "la memoria histórica" e íntimamente ligada a ella su patrimonio implica hacer un ejercicio de humildad, solidaridad, perdón, acogimiento e inmersión en los sentimientos del "otro". Desde que años atrás se elaboró la llamada Ley de memoria histórica, ésta ha permanecido semi dormida hasta la llegada, en mi opinión, de algunas fuerzas políticas que han aflorado en la escena pública en los últimos tiempos y han reavivado el debate. Evidentemente se ha comenzado por el elemento más representativo de la Guerra Civil, el Valle de los Caídos, un bien patrimonial distintivo de los que "ganaron" la guerra, si es que en una guerra gana alguien.

Por recordar mínimamente, este monumento se construye con el esfuerzo y la vida de muchas personas, presos republicanos, trabajadores a sueldo, personas

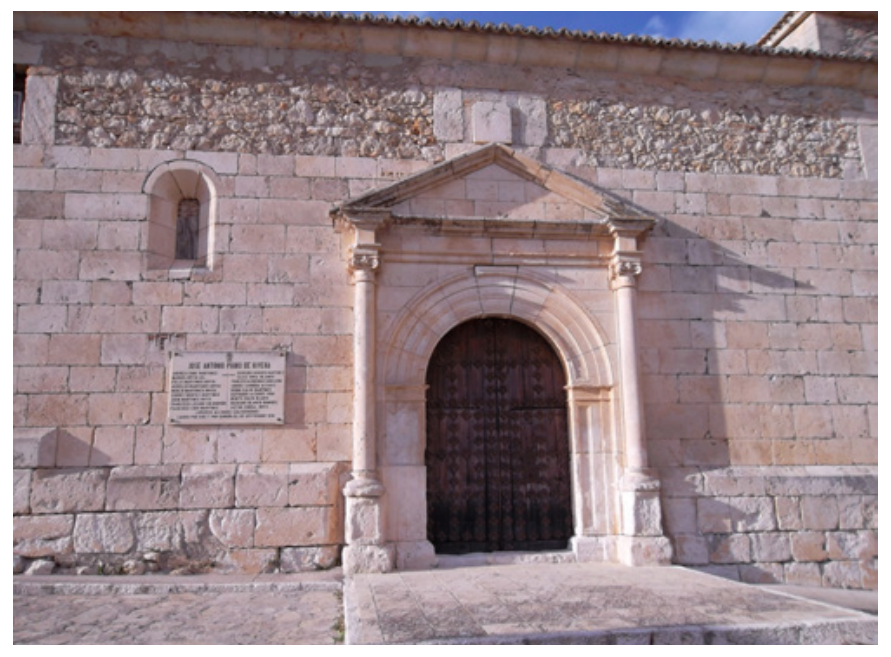

Lápida conmemorativa por los caídos en la guerra civil (1936-39) en la fachada principal de la iglesia situada en el municipio de Loranca de Tajuña (Guadalajara) | foto Oilisab afines a la causa franquista, etc., es decir un totum revolutum de individuos con ideas, afinidades, necesidades y situaciones muy distintas que hicieron posible esta construcción. Ciertamente el régimen franquista consideró siempre que "el valle" daba culto a los caídos del bando nacional, pero creo que esa visión debe ser desechada si nos atenemos a las personas que allí están sepultadas como consecuencia de las obras llevadas a cabo. Es llamativo que pocas veces se haya incidido en esta consideración pues creo que la misma es fundamental para que de forma definitiva, aquello sea considerado como el cementerio común de todos los caídos en la Guerra Civil (1936-39).

Es verdad que enterrar al dictador en aquel edificio no ayuda a restañar las heridas y esta sea la causa principal para que algunos propongan hasta su voladura, sin detenerse en valorar lo que este emplazamiento significa como valor histórico de primer orden. Pasados casi 80 años del fin de la contienda, superada la dura etapa de la postguerra y viviendo actualmente en un periodo democrático como nunca ha tenido España, es hora de valorar este patrimonio desde un punto de vista estrictamente cultural, histórico y por qué no, educativo para las generaciones futuras de lo que supone una guerra. Seguir empeñados en buscar quiénes fueron los buenos y quiénes los malos es un ejercicio que no lleva a nada positivo, muy al contrario, impide construir un futuro democrático sin vinculaciones pasadas, asumir el dolor sufrido por las familias de los dos bandos es tan fácil como ponerse en el lugar del otro.

Si nos detenemos brevemente en revisar lo que hoy es una gran parte de nuestro patrimonio histórico, tanto en España como en cualquier otro país de Europa, podremos comprobar que la mayoría de los edificios, monumen- 
tos de todo tipo, esculturas y hasta la pintura responden a representaciones de los periodos de dominación reinante en cada momento histórico. Solo por señalar algunos ejemplos: en la antigua Roma la Columna Trajana representa en sus bajo relieves, con todo lujo de detalles, la conquista de la Dacia por el emperador Trajano, si en aquellos momentos alguien se le hubiera ocurrido destruirla, hoy no podríamos observarla y valorar su riqueza escultórica. Igual ocurre con el obelisco de la plaza Vendôme en París, Napoleón decide erigir este monumento para resaltar sus hazañas, afortunadamente ahí sigue, aunque hubo intentos de destruirlo, hoy solo tiene un valor patrimonial y turístico.

Reconsideremos el tema y hagamos un ejercicio de sentido común, ¿Qué sería de nuestra memoria colectiva si gran parte del patrimonio que hoy poseemos hubiera sido volado o destruido por ideas políticas?, sin duda, esta acción irresponsable imposibilitaría en gran medida que las generaciones futuras pudieran conocer y de alguna manera evitar errores del pasado y seríamos mucho más pobres en todos los aspectos ya que se habría perdido una gran fuente de conocimiento y perspectiva histórica que estos monumentos nos facilitan en la actualidad.

Es paradójico que, siendo considerado nuestro país como una democracia consolidada, persistan actitudes tan totalitarias incapaces de conjugar "valor histórico" con "valor simbólico" y este enfrentamiento solo deja entrever que aún no hemos sido capaces de superar etapas pasadas de nuestra historia reciente. Las democracias fuertes y consolidadas han aprendido a mantener una cierta distancia con hechos históricos del pasado dejando de lado los sentimientos de unos y otros y considerando todo su patrimonio como algo identitario, propio, que forma ya parte de su bagaje histórico del que no podemos sustraernos ni olvidarnos y todos (historiadores, administración, experto en patrimonio y de una forma muy especial la misma ciudadanía) debemos hacer un esfuerzo por situarnos en posiciones "neutras", solo de esta manera nuestro patrimonio podrá ser considerado como algo ajeno a lo sentimental.
Ante esta situación creo que ha llegado el momento de hacernos algunas preguntas con el fin de intentar resolver la cuestión, propongo las siguientes: ¿El dolor por mis muertos es el mismo que el de los otros?, la respuesta es un sí rotundo; ¿Mis ideas políticas deben prevalecer sobre la de los otros?, absolutamente no; ¿Una guerra, entre hermanos, debe suponer un perdón mutuo?, no tengo duda alguna de que la respuesta debe ser sí. En mi opinión estas respuestas son claves para asumir lo que pasó. Pero no solo hemos de asumir estas respuestas como propias sino también aceptar algunos elementos externos a nivel simbólico, aunque puedan distorsionar nuestra actitud conciliadora, pues si queremos proyectar una idea de historia democrática se hace imprescindible convivir con ellos y permitir que calles, colegios, instituciones, etc. lleven nombres de todos los "participantes" en la Guerra Civil y admitir que lo ocurrido en ese enfrentamiento fue producto de un momento histórico concreto, en muchos aspectos difícil de entender para nuestra mentalidad actual. Su recuerdo solo debe servirnos como lección para no volver a incurrir en los mismos errores del pasado.

En cualquier caso, el exacerbado deseo de recordar acciones nefastas de una guerra y sobre todo a sus dirigentes no deja de parecerme algo morboso que nos impide avanzar hacia una sociedad democrática, igualitaria y consciente de su pasado. El recuerdo es necesario, pero cuando se convierte en obsesión anula cualquier posibilidad de asumir los hechos con serena imparcialidad. 